\title{
Candida biofilms properties and where we are now?
}

\author{
Mohammed Ahmed Alem
}

Jeddah Eye Hospital, Laboratory Directorate, Ministry of Health, Jeddah, Saudi Arabia

Correspondence Author: Mohammed Ahmed Alem, Jeddah Eye Hospital, Laboratory Directorate, Ministry of Health, Jeddah, Saudi Arabia Email: Mohammed_3lem@hotmail.com

Received date: 12 May 2019, Accepted date: 24 September 2019, Online date: 5 October 2019

Copyright: (C) 2019 Mohammed Ahmed Alem. This is an open-access article distributed under the terms of the Creative Commons Attribution License, which permits unrestricted use, distribution, and reproduction in any medium, provided the original author and source are credited.

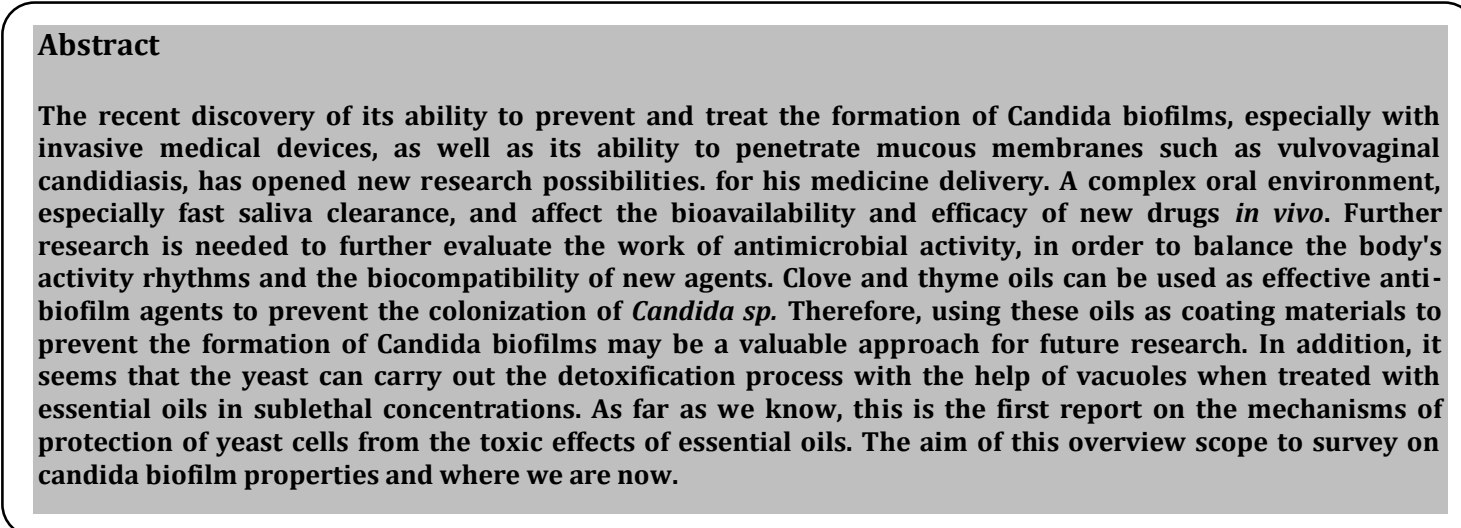

Keywords: Candida, biofilm, yeast, antimicrobial

INTRODUCTION

The discovery of compounds that inhibit the synthesis of the cell wall of fungal glucans in 20 years, as evidenced by the echinocandins, and the like, because of the rapid translational studies led to the global recognition of echinocandins as the main treatment for invasive candidiasis (C) and in patients without neutropenia and candida biofilm [1-2]. The action of the echinocandins Aspergillus sp. and in combination were studied, through monotherapy azoles as the initial and for the rescue treatment of Invasive Aspergillosis (A) experience as a febrile neutropenia treatment. Increasingly used in clinical practice, and IC is the best treatment but in the second-line lorem. The echinocandins demonstrate good activity in vitro and in vivo (animal models) and to prevent the formation of biofilms and his achievements in the study of biofilms "surface coating" from a variety of medical devices. Invasive, however, in the class of drugs, such echinocandins the face of the failures is because of the indigence of one of the mouths of the composition of, and the care of the liver, and the prince of the costs of cardiac toxicity. In addition, the recent rise all' echinocandin encountering resistance, especially in Candida glabrata, up to $15-25 \%$ in some centers [3]. What is the molecular mechanisms of resistance are in all' echinocandin, are well known, and among these mutations in the gene of a gene FRS is repeated, the wall of the little room to the synthesis of the beta $(\beta)$, D glucan, if the resistance of the fact that the clinical use of the advice of the masters, in evil all' echinocandin, a view of the duration of the treatment, and take measures with a significant risk of shall be the thoughts of the echinocandin. We are talking about echinocandins of the wider use of parenteral administration and the work of the dose, high costs, and emerging war. And after that clinical experience shows the side-effects of his new understanding of the possible toxicity of the heart. We highlight the new role in the prevention and treatment candida biofilm and its immunomodulatory role. We also deal with a new dosing strategy that can facilitate the reduction of hydrogen outpatient treatment, possibly reducing the toxicity of drugs, as well as highlighting the recent development and exciting belongs echinocandin CD101 and the long duration of action as in fig 1.

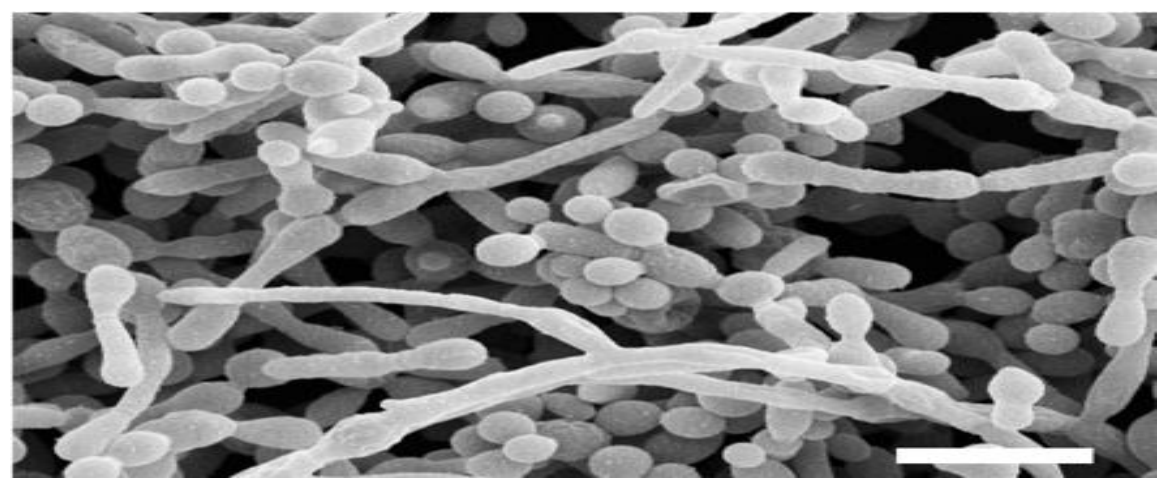

Fig 1. SEM image of a mature C. albicans biofilms (48 h). That is a combination of elements and pseudo-fake yeast biofilms [4]. 
Citation: Mohammed Ahmed Alem, 2019. Candida biofilms properties and where we are now? Journal of Applied Sciences Research., 15(5): 34-39. DOI: 10.22587/jasr.2019.15.5.7

The aim of this overview scope to survey on candida biofilm properties.

\section{Recent advances in clinical application \\ Role in biofilms}

In recent years, the interest in the pathogenesis of Candida biofilms formation of invasive medical devices can be substantially increased with the increasing use of the medium and long term. Candidiasis infections and medical devices are expensive and difficult to manage. He associated with a central venous catheterrelated disease was $11.5 \%$ of $(\mathrm{CVC}), 1 \%$ of the peritoneal dialysis vice prosthetic joint infections and infections of the catheter 2,6-7\% of $2-9 \%$ of the cardiac prosthesis. valvular endocarditis, pacemaker $4.5 \%, 1 \% 21 \%$ ventriculoperitoneal shunt is associated with catheters and urinary tract infections summarized in [5]. Morbidity and mortality infection usually requires a highly placed his hand thoughts. Biofilms are all attached to the three-dimensional city of biotic and abiotic integers or incorporated into the cellular matrix, which may be of continuing medical device surfaces, such as CVC or joint prostheses, and mucosal surfaces such as gastrointestinal tract or the vaginal mucous membrane [6]. The drug penetration host's immune response to avoid problems.

A conventional biofilm infection is not particularly susceptible to treatment. In addition, it should be noted that increases in a complex bidirectional interaction between bacteria polymicrobial biofilms can perform both forms proliferate. Aspergillus sp. It mainly involves the fungus and most studied in bacterial, fungal polymicrobial reasons as those which occurred in various places, such as in the oral cavity, gastrointestinal tract, localized damage the integrity of the arrangements, the colonization of the respiratory tract and indwelling catheters [6]. Echinocandins have a unique opportunity to antifungal drugs by the White destroy biofilms in both model's infection in vitro and in mammals, Interest cells in C. albicans; yeast $\beta$-glucan are present in the layer external mannoproteins and inaccessible to the immune system widely [7] is interesting, as they would be unwilling or allowed sub-inhibitive concentrations of caspofungin mask and casts $\beta$ glucan as a change mushroom of $\beta$-glucans exposed to stronger binding to the dextrin-1, which stimulates an increase in the levels and consumer cytokines independent of $\beta$-glucan (Wheeler and Fink 2006). race of medical devices aged on caspofungin [8] coating covalent caspofungin. The gas plasma polymerization to be transferred from small colonies from the wells of silicon pl Wafer 12. C. and C. tropicalis agent> 98\% compared to control. That was demonstrated as early as the late silicon surface on the formation of $C$. albicans covalently immobilized caspofungin inhibits biofilms C. albicans [9-10].

Twenty years for echinocandin research, after 10 years of post-marketing experience, but also to discover new challenges, cardiac toxicity of the sea and all the ways to control the molecular center. At the same time, they signify the progress of this we make a sure, among the parts of his exciting. prevent the formation of bacteria in biofilms fungi, and the ability to immunomodulate and new synergistic adjuvants and compositions for topical application of long-term action. The progress achieved to date indicates the continuing importance of interdisciplinary research, covering the broadest areas of biomedicine, chemistry, engineering, molecular medicine and computer research in the development of therapy [10].

\section{Novel Approaches to the Control of Oral Microbial Biofilms}

In the mouth biofilms candida, people in the formation of microbes embedded in a wide variety of extracellular polysaccharides in a self-organized array (EPS), which is recognized as a factor in many of the virulence of the diseases such as tooth decay and dental gingivitis and periodontitis disease Periapical. periimplantitis and periodontitis [11-15]. Control of oral biofilms results in significant costs worldwide [16]. Our understanding of biofilms with more information about the new growth of new technologies and genetic pathways, physiological responses and intracellular signal transduction pathways. It has grown considerably since its first official definition in the mid-1980s [17,18]. The life cycle of a conventional biofilm involves bacterial fixation, growth/maturation of biofilms, and disintegration of the biofilms. Measures that can interrupt any stage.

Biofilms similar approach to the control of biofilms potential. Due to the complexity of the oral cavity and rapid removal from the saliva, antibacterial agents administered to the appropriate concentration long enough to hold it [19]. The bacteria present in plankton, she often requires higher concentrations of the antimicrobial agents to destroy biofilm candida [11,20,21]. If to be mixed with the antimicrobial drugs, such planktonic which exhibits all the cells, the cells at the full dose [22], is able to access to its own biofilm candida as long as the matrix is to lessen the abuse of drugs, so they ought not to penetrate into the innermost parts. [23-27] The number of drugs in the deep layer.

The recent studies have shown that it is not only will you save, PES, and the maturation of the womb among the scaffold to the growth of biofilm candida, biofilm candida, but also provides for the emergence of the properties of, and look forward to between the surface of heterog eneous faith that comes from the Light at the local, spatial, and a synergistic interaction. Antimicrobial Agents and tolerance to increased competitive [24,28]. On the other hand, the many ways to not only cost-effective control of biofilm candida.

The increased resistance to other antibiotics, Antimicrobials. agents $[17,26]$. The antimicrobial agent's development initiatives to study the emergence of antibiotic-resistant bacteria from a tree trying out new [29]. The ideal facilitates access to antibiotics is the disintegration of biofilms formed and hinders the formation of a new set of pathogens biofilm candida remove any cause, who was most dysbiosis micro-ecology [30-33]. Some of the new treatment of antibiotics is different from the traditional developer aimed to Chlorhexidine the individual's own goal on the properties and vices biofilms biofilm candida, or to eliminate the mouth biofilm candida and the resistance [11] drug. These new strategies to prevent the defection of some inhuman of reviews on the shores of biofilms present between the nanomaterials, the quaternary of ammonium salts, arginine, and a small amount of the molecules of the natural products.

\section{Nanomaterials}

Changes nanomaterials concept for what has happened and discovered what would have happened in the 80s, because nanomaterials are many cats, including the surgeon will offer broad prospects for development. [34]. How nanomaterials, silver, copper, zinc, zinc oxide, titanium oxide, and graphene nanoparticles can be used to control biofilm candida formation [35-37]. It is suggested that the polyethyleneimine, quaternary ammonium, and silica Chitosan nanoparticles are effective to control biofilm candida $[35,38,39]$. Some metallic mouth biofilm candida nanomaterials demonstrate their ability to control. These include silver nanoparticles and silver nitrate (agent) of the mouth of pathogens [42]. The disadvantage is that silver nitrate, the color of the dentin [15, 43, 44], and the silver coating directly prevent the formation of dentin can prevent bacterial growth and biofilm candida dentin surfaces surrounding environments, offering hope and potential. When a plaque and secondary functions are applied to the membrane, as in $[15,45]$.

\section{Effect of Clove and Thyme Essential Oils on Candida Biofilm Formation}

Some species of the genus Candida are responsible for infections associated with the formation of biofilms, which are considered as an important factor in virulence. Candida strains that form biofilms associated with increased patient mortality probably correlate with low matrix permeability for antifungal drugs [46]. The risk of developing candidiasis infections is associated not only with biofilm formed in medical devices such as catheters, implants, stents, accessories, and artificial valves but also with biofilm produced in food products and food packaging surfaces. [47]. Candida Biofilm is a well-organized, three-dimensional and heterogeneous structure consisting of forms of planktonic and mycelial yeast surrounded by extracellular polymeric substances (EPS). The cells of the biofilm structure are interdependent in the quorum detection system and are characterized by phenotypic properties that are different from the properties of floating plankton cells [48]. The structure of the biofilm increases the effectiveness of microbial protection from adverse effects.

Environmental factors, including antibiotics, reduce the effectiveness of the protective mechanisms of the body and contribute to the absorption of nutrients [49]. Biological mechanisms that reduce the sensitivity of yeast biofilms to antifungal drugs are associated with an active release of the drug, limited by the penetration of the drug due to the extracellular matrix, low metabolic activity of cells in a mature biofilm, and different gene expression in a biofilm than in planktonic forms [50,51]. Active drug outflow plays a key role in the early resistance of biofilm development [51]. The role of the extracellular matrix in the drug resistance of a biofilm is apparently less important since resistance occurs shortly after adhesion of $C$. albicans to surfaces before the formation of EPS [52]. The role of the matrix in resistance is rather related to maintaining the integrity of the biofilm and restricting cell access to several connections. In addition, the PES matrix does not affect the reduction of drug diffusion, and the diffusion process does not depend on the structure and maturity of the biofilm [53]. Drug resistance can also be a consequence of poor metabolic activity and slow cell growth in a mature biofilm.

Nevertheless, studies of the controlled growth rate of $C$. albicans biofilm show that the relationship between drug resistance and growth rate refers only to planktonic forms, and not to the biofilm phenotype [54]. An essential attribute of a biofilm is also the ability to produce a small population of resistant cells that are extremely resistant to antifungal drugs [55]. Resistant drug resistance is the result of a metabolic latent state of cells and is independent of the composition of 
the cell membrane and expression of pump outflow. Due to the resistance of Candida Biofilm to traditional antifungal therapy, effective methods of treatment and prevention should be developed. Considering the results associated with the strong antifungal activity of essential oils [56], the question arises of their effectiveness of antibiofilm. In addition, an important attribute of essential oils is their natural origin and the fact that, until now, the acquisition of the resistance of microorganisms to essential oils has not yet been observed [56].

\section{Gaining Insights from Candida Biofilm Heterogeneity is the heterogeneity of biofilms}

Traditional molecular microbiological approaches suggest that the elimination or overexpression of some genes allows us to finally determine their function. These tactics, supported by structural biology studies, allow us to determine the structure/function of individual proteins in the context of the pathogenic capacity of microbes. However, this suggests that molecular manipulations do not have pleiotropic effects and do not consider the intrinsic biological heterogeneity that applies to various clinical isolates. This raises the question of whether the use of laboratory strains is the best way to develop our understanding of microbial pathogenesis [57], or rather, if a combined approach to evaluate the phenotypic and genotypic properties of clinical isolates improves our understanding. This review focuses on Candida biofilms and attempts to examine the literature on the information that can be obtained by working with clinical isolates and observing their intrinsic heterogeneity.

\section{Investigate biofilm formation}

Quantitative methods are an important factor in understanding and evaluating biofilm formation in important species of Candida. In the study of large collections of clinical isolates obtained from different groups of patients, different experimental strategies consisting mainly of quantifying biomass in dry weight, were used, including dyes such as purple crystalline dye and TXT dye. 58]. Each method has its advantages and disadvantages, but caution should be exercised when interpreting the data for each test, especially when associated with clinical results. Given the heterogeneity observed between strains and the diversity of models and laboratory methods, standardization becomes problematic. For example, the two most commonly used vectors for biofilm formation are the Roswell Park Memorial Institute (RPMI) and Spider. Studies have shown that RPMI contributes the most to the formation of biofilms and stimulates biofilms three times more frequently than Spider Media [59]. In addition, these environments are not physiologically significant because in many studies artificial saliva, urine and mammalian serum are used for the formation of biofilms under biologically more favorable conditions. [60]. The sodium salt of XTT (2,3-bis (2-methoxy-4-nitro5-sulfenyl) -2H-tetrazolium-5-carboxamide) [61,62] is one of the most commonly used. This biofilm analysis is highly reproducible and guarantees the high performance of different microtiter plates without compromising accuracy. Its advantages are associated with sensitivity tests that allow direct comparison of treated samples with antifungals and untreated controls [63]. Given the observed metabolic differences between strains and species, a measure of the development of the biofilm to be tested should be interpreted with caution as it may simply reflect many cells [64, 65]. numbers [66,67]. For example, rare non-apricot yeast biofilms may have high XTT values with minimal biomass. Therefore, the result obtained by XTT is solely related to cell viability and does not take into account other components of biofilms such as extracellular matrix (ECM) [68].

Another test commonly used to form a biofilm is the crystalline purple color. This method provides a complete quantitative assessment of biomass biofilms (cells and MEK) and allows fast and high throughput processing for multiple samples. However, since the variability of the washing phase does not allow for subtle differences between the test samples, biomass can lead to both overestimation and underestimation [58]. An interesting example is described in a recent study using these methods to stratify the ability of Candida blood isolates to form biofilms [69]. There was no apparent standard for stratification, indicating that the strains were biofilms or biofilm-free agents with purple values greater than OD570>0.09, only biofilm-forming agents. It was concluded that non-Candida albicans species (NCAS) produced a larger biofilm than C. albicans and that biofilm formation was not related to clinical outcome.

This contradicts the richness of the previous literature, according to which the ability of Candida isolates to form biofilms was associated with mortality [70-73]. The differences between these results show the need for standardized tests to determine biofilm risk factors. Our group has adopted the "belt and braces" approach using a combinatorial approach of quantitative quantification of fluorescent crystalline biofilms, XTT and SYTO®9 (Thermo Fisher Scientific, Paisley, UK). Significant correlations were found here for the formation of the C. albicans biofilm, which was then used to stratify the biofilm formation ability [70]. Regardless of the quantitative approach, greater heterogeneity of biofilms is observed in different clinical groups of isolates $[69,70,74,75]$. Taken together, these data indicate that different Candida strains work differently and that individual isolates should be considered to understand their clinical importance in relation to antifungal resistance and pathogenic potential as in fig 2. [76].

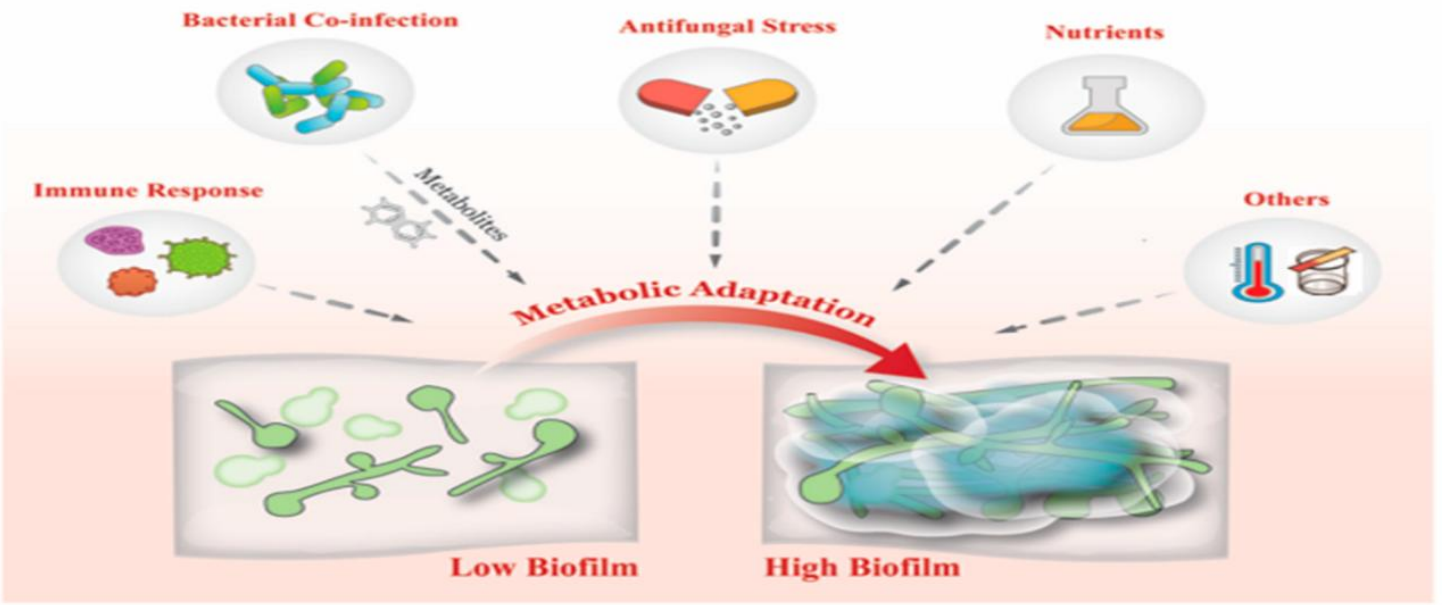

Figure 2. Factors influencing biofilm formation [76].

\section{How the Fungal Pathogen Candida auris was Able to Emerge Globally in Healthcare?}

Every year, around 1.5 million people die from invasive fungal infections [77]. Lorem increased immunosuppressive life expectancy increased an increase in the survival of cancer patients and the patient, as well as the use of catheters, do not pay attention to the appearance of opportunistic fungal pathogens in recent decades [78, 79]. Aspergillus species are considered more common in hospitals, fungi are more than 400,000 cases of blood poisoning every year, making it the third or fourth most important cause of invasive fungal infections worldwide. [80-82]. Candida albicans is the main responsible for India recognized candidiasis [77]. However, new species are on the rise, such as drug-resistant drugs, white ear, -medication-resistant to the arrival of the world, is one of the most disturbing examples. C. for antifungal treatment options are limited due to resistance to ear, identification errors, and the ability to permanently colonize hospital care. Since its first description in 2009 , more than 25 countries of the five C. continents recorded in the ears, causing fungal outbreaks overall mortality rate was $32 \%$ at 66 [83-85]. Is genus aspergillus being a very heterogeneous group composed of species, C. auris differs from the well-studied and very wide range of pathogenic species Candida albicans and C. glabrata and C. [86, 87]. For example, if in other chrysogenum Aspergillus niger Penicillium, the infection of the host by the thought that it would have been due to the Flora of the East part: A has the unique ability to be forever, and marched the colonies in the skin to the ear, making it more easily transmitted among patients [86,88]. there are transmissible mortality rates and high resistance multiresistant $\mathrm{C}$. constitute a serious threat to the health of the ear of the public, C auris. A total of C sheets of the paper epidemiology ear (revision [88-90]. However, the mechanisms of it, and Sclcrotium cepivorum Fludioxonil increasing virulence of which have recently [91]. Global pathogenic nosocomial. C. What is the plague ear of 2009 tells us to put into white what is 
said in the ear of the information like all types haemulonii C (Metschnikowiaceae disaster), after 70 years of isolation and willingly a Japanese ear canal [92]. Unfortunately, often incorrectly identified as C. orecchio C. haemulonii Candida Famata and commercial Rhodotorula glue along the same diameter. Microscan systems such as (Beckman Coulter, Pasadena, CA) and API AUX-20C. Therefore, fast and safe what this region of the matrix, laser systems require Oramineae desorption of ionization (MS bristles t) following the same region has different internal or writing (it). yeast [93,94]. Earlier, in the annals of C. ear lack of library made impossible for research biotypic Bruker systems maltitol for the ear. However, access to the updated database, since ear is the same [95]. A retrospective study from white isolated from three cases of nosocomial fungus told South Korea in all cases up to C shows the ear, the oldest report in 1996 [96]. However, it is well known that in India there has recently become C. nosocomial world ear. Complete sequencing (WGS) of clinical isolates of C. coating led to a description of four unique ears, divided by geographical region (East Asia, South Asia, South Africa, and South America). WGS analysis showed thousands of disasters were separated by an additional information zoom (SNP), but is converted to a clonal isolate. The ear is touched, and almost at the same time indicates, C. auris. This independent clonal analysis, three of the people on the continent [87]. The genomes of many species of Aspergillus niger Albicans pathogens, and $C$. auris and C. glabrata, have been the subject of numerous studies, while the high-quality C. nocivo ear was only recently studied [97-100]. Contrary to the recent C. parasitic attempts sequence, detailed information is available on the architecture of the parasite, increasing virulence and the rest of the multi-drug resistance in $C$. auris. $C$. hemulonia, duobushaemuloni C. and C. pseudohaemuloni accounted for $88 \%$ [100]. Furthermore, $40 \%$ of the predicted proteins were compared with orthologues C. Portugal [99]. However, many of these proteins are atypical and hypothetical proteins. It therefore remains to be determined whether it is a highly pathogenic C. virulent and moral ear. The comparison with the plague of the plague ear of $C$. albicans, is increasingly studied, it must be observed, however, but correlated: they had suggested the presence of a significant series of orthologues, which is to contribute to the virulence of your attacks to be able to breathe Caius s. This is a set of orthologues among the main transporters involved in race and classes ABC (Hardcover binding protein) secreted fungi, lipase, and phospholipase aspartyl protease $[97,99]$.

\section{CONCLUSION AND FUTURE PERSPECTIVES.}

Due to drug resistance, we pay more attention. Identify alternative agents for biofilm control. Precision, the efficacy, and effectiveness of oral targeting of the biofilm were emphasized. New nanomaterials capable of loading antimicrobial drugs or being drugs in themselves can accurately affect in India, the answer specific problems. A dental adhesive resin to be incorporated into environmental incentives are less of the second hour of the best out of the activity of the reason for which he acts as an antibacterial. Even small molecules designed for individual key elements of bacterial adhesion to interrupt the mouth oral biofilms. As it were, from the mouth of the bacteria, and they can be the subject of oral arginine Biofilm eco modulator, and not to the forms of tooth decay.

Further, the group of products and the operation of an antibiotic that contains natural polyphenols has an antimicrobial and low tolerance to drugs. Oral biofilm in the mouth. However, it should be noted that current data are available. It is mainly the study of the use of biofilms made from glass, or of one of the species of the animal. Infectious polymicrobial nature of tooth decay and periodontal disease will limit the clinical translation of the approaches developed based on a single biofilm. In extensive laboratory studies fit, which led to a better understanding of Candida biofilm. However, there is an essential reason for these studies based on human health and clinical in Candida biofilms desire to find new therapeutic targets. Thus, the guide therapeutic methods for studying artificial limit our potential. To present some ideas, the latest information to help get the information they need in order to benefit from clinical isolates. He gazed at the following conditions on how these rules it is a real change for the better can not only support high strains, and the understanding of the clinical, as much in the level of phenotypic genotypic. Phenotypes Candida biofilm and better in some way to develop a new antibiotic therapy.

\section{CONFLICT OF INTEREST}

The authors declare no conflicts of interest.

\section{ACKNOWLEDGMENT}

The author support from the Jeddah eye hospital, Laboratory Directorate, Ministry of Health, Jeddah, Saudi Arabia

\section{REFERENCES}

[1] Alothman AF, Al-Musawi T, Al-Abdely HM, Salman JA, Almaslamani M, Yared N et al (2014) Clinical practice guidelines for the management of invasive Candida infections in adults in the Middle East region: expert panel recommendations. J Infect Public Health 7(1):6-19.

[2] Pappas PG, Kauffman CA, Andes DR, Clancy CJ, Marr KA, Ostrosky-Zeichner L et al (2016) Clinical practice guideline for the management of candidiasis: 2016 update by the infectious diseases' society of America. Clin Infect Dis 62(4):e1-e50.

[3] Vallabhaneni S, Cleveland AA, Farley MM, Harrison LH, Schaffner W, Beldavs ZG et al (2015) Epidemiology and risk factors for echinocandin nonsusceptible candida glabrata bloodstream infections: data from a large multisite population-based Candidemia Surveillance Program, 2008-2014. Open Forum Infect Dis 2(4): ofv163.

[4] Gordon Ramage, Stephen P. Saville, Derek P. Thomas, and Jose 'L. Lo'pez-Ribot (2005) Candida Biofilms: An Update, EUKARYOTIC CELL, Apr. p. $633-638$.

[5] Kojic EM, Darouiche RO (2004) Candida infections of medical devices. Clin Microbiol Rev 17(2):255-267.

[6] Katragkou A, Roilides E, Walsh TJ (2015) Role of echinocandins in fungal bioflm-related disease: vascular catheter-related infections, immunomodulation, and mucosal surfaces. Clin Infect Dis 61(Suppl 6): S622-S629.

[7] Wheeler RT, Fink GR (2006) A drug-sensitive genetic network masks fungi from the immune system. PLoS Pathog 2(4):e35

[8] Coad BR, Griesser HJ, Peleg AY, Traven A (2016) Anti-infective surface coatings: design and therapeutic promise against device associated infections. PLoS Pathog 12(6):e1005598.

[9] Kucharikova S, Gerits E, De Brucker K, Braem A, Ceh K, Majdic G et al (2016) Covalent immobilization of antimicrobial agents on titanium prevents Staphylococcus aureus and Candida albicans colonization and bioflm formation. J Antimicrob Chemother 71(4):936-945.

[10] Chang C. C., - M. A. Slavin - S. C.-A. Chen (2017). New developments and directions in the clinical application of the echinocandins, Arch Toxicol (2017) 91:1613-1621.

[11] Davies, D. "Understanding bioflm resistance to antibacterial agents," Nature Reviews Drug Discovery, vol. 2, no. 2, pp. 114- 122 , 2003.

[12] Ricucci D. and J. F. Siqueira Jr., "Bioflms and apical periodontitis: study of prevalence and association with clinical and histopathologic fndings," Journal of Endodontics, vol. 36, no. 8, pp. 1277-1288, 2010.

[13] Noiri, Y., A. Ehara, T. Kawahara, N. Takemura, and S. Ebisu, "Participation of bacterial bioflms in refractory and chronic periapical periodontitis," Journal of Endodontics, vol. 28, no. 10, pp. 679-683, 2002.

[14] Liljemark, W. F. and C. Bloomquist, "Human oral microbial ecology and dental caries and periodontal diseases," Critical Reviews in Oral Biology Medicine, vol. 7, no. 2, pp. 180-198, 2016.

[15] Besinis, A., T. De Peralta, and R. D. Handy, "Inhibition of bioflm formation and antibacterial properties of a silver nano-coating on human dentine," Nanotoxicology, vol. 8, no. 7, pp. 745-754, 2014.

[16] Beikler T. and T. F. Flemmig, "Oral bioflm-associated diseases: Trends and implications for quality of life, systemic health and expenditures," Periodontology 2000, vol. 55, no. 1, pp. 87-103, 2011.

[17] Flemming, H.-C. J. Wingender, U. Szewzyk, P. Steinberg, S. A. Rice, and S. Kjelleberg, "Bioflms: An emergent form of bacterial life," Nature Reviews Microbiology, vol. 14, no. 9, pp. 563-575, 2016.

[18] Liang, Y., L. Yang, W. Hong et al., "Current understanding of multi-species bioflms," International Journal of Oral Science, vol. 3, no. 2 , pp. 74-81, 2011.

[19] Horev, B., M. I. Klein, G. Hwang et al., "PH-Activated nanoparticles for controlled topical delivery of farnesol to disrupt oral bioflm virulence," ACS Nano, vol. 9 , no. 3, pp. 2390-2404, 2015 .

[20] Stewart, P. S. and J. W. Costerton, “Antibiotic resistance of bacteria in bioflms,” e Lancet, vol. 358, no. 9276, pp. 135-138, 2001.

[21] Benoit, D. S. W. and H. Koo, “Targeted, triggered drug delivery to tumor and bioflm microenvironments,” Nanomedicine, vol. 11, no. 8, pp. 873-879, 2016. 
Citation: Mohammed Ahmed Alem, 2019. Candida biofilms properties and where we are now? Journal of Applied Sciences Research., 15(5): 34-39. DOI: 10.22587/jasr.2019.15.5.7

[22] Costerton, J. W. P. S. Stewart, and E. P. Greenberg, "Bacterial bioflms: a common cause of persistent infections," Science, vol. 284, no. 5418, pp. 13181322, 1999.

[23] Van Acker H., P. Van Dijck, and T. Coenye, "Molecular mechanisms of antimicrobial tolerance and resistance in bacterial and fungal bioflms," Trends in Microbiology, vol. 22, no. 6, pp. 326-333, 2014.

[24] Lebeaux, D., J.-M. Ghigo, and C. Beloin, "Bioflm-related infections: bridging the gap between clinical management and fundamental aspects of recalcitrance toward antibiotics," Microbiology and Molecular Biology Reviews, vol. 78, no. 3, pp. 510-543, 2014.

[25] Liu, Y., A. C. Kamesh, Y. Xiao et al., "Topical delivery of lowcost protein drug candidates made in chloroplasts for bioflm disruption and uptake by oral epithelial cells," Biomaterials, vol. 105, pp. 156-166, 2016.

[26] Bowen, W. H., R. A. Burne, H. Wu, and H. Koo, "Oral Bioflms: Pathogens, Matrix, and Polymicrobial Interactions in Microenvironments," Trends in Microbiology, vol. 26, no. 3, pp. 229-242, 2018.

[27] Xiao, J., M. I. Klein, M. L. Falsetta et al., "Te exopolysaccharide matrix modulates the interaction between 3D architecture and virulence of a mixed-species oral bioflm," PLoS Pathogens, vol. 8, no. 4, Article ID e1002623, 2012.

[28] Koo, H., J. Xiao, and M. I. Klein, "Extracellular Polysaccharides Matrix - An Ofen Forgotten Virulence Factor in Oral Bioflm Research," International Journal of Oral Science, vol. 1, no. 4, pp. 229-234, 2009.

[29] Baltzer S. A. and M. H. Brown, "Antimicrobial peptides- promising alternatives to conventional antibiotics," Journal of Molecular Microbiology and Biotechnology, vol. 20, no. 4, pp. 228-235, 2011.

[30] Rabin, N., Y. Zheng, C. Opoku-Temeng, Y. Du, E. Bonsu, and H. O. Sintim, "Agents that inhibit bacterial bioflm formation," Future Medicinal Chemistry, vol. 7, no. 5, pp. 647-671, 2015.

[31] Gao, L. and H. Koo, "Do catalytic nanoparticles ofer an improved therapeutic strategy to combat dental bioflms?" Nanomedicine, vol. 12, no. 4, pp. 275$279,2017$.

[32] Wu, H., C. Moser, H.-Z. Wang, N. Høiby, and Z.-J. Song, "Strategies for combating bacterial bioflm infections," International Journal of Oral Science, vol. 7, pp. 1-7, 2015.

[33] Chen L. and Y. Wen, "Te role of bacterial bioflm in persistent infections and control strategies," International Journal of Oral Science, vol. 3, no. 2, pp. 6673, 2011.

[34] Hulla, J., S. Sahu, and A. Hayes, "Nanotechnology: History and future," Human \& Experimental Toxicology, vol. 34, no. 12, pp. 1318-1321, 2015.

[35] Allaker R. P. and K. Memarzadeh, "Nanoparticles and the control of oral infections," International Journal of Antimicrobial Agents, vol. 43, no. 2, pp. 95104, 2014.

[36] Hemeg, H. A. "Nanomaterials for alternative antibacterial therapy," International Journal of Nanomedicine, vol. 12, pp. 8211-8225, 2017.

[37] Rai, M. K., S. D. Deshmukh, A. P. Ingle, and A. K. Gade, "Silver nanoparticles: the powerful nanoweapon against multidrugresistant bacteria," Journal of Applied Microbiology, vol. 112, no. 5, pp. 841-852, 2012.

[38] Besinis, A., T. De Peralta, C. J. Tredwin, and R. D. Handy, "Review of nanomaterials in dentistry: interactions with the oral microenvironment, clinical applications, hazards, and benefts," ACS Nano, vol. 9, no. 3, pp. 2255-2289, 2015.

[39] Shrestha, A., S. Zhilong, N. K. Gee, and A. Kishen, "Nanoparticulates for antibioflm treatment and efect of aging on its antibacterial activity," Journal of Endodontics, vol. 36, no. 6, pp. 1030-1035, 2010.

[40] Hannig M. and C. Hannig, "Nanomaterials in preventive dentistry," Nature Nanotechnology, vol. 5, no. 8, pp. 565-569, 2010.

[41] Cheng, L., K. Zhang, M. D. Weir, M. A. S. Melo, X. Zhou, and H. H. K. Xu, "Nanotechnology strategies for antibacterial and remineralizing composites and adhesives to tackle dental caries," Nanomedicine, vol. 10, no. 4, pp. 627-641, 2015.

[42] Besinis, A., T. de Peralta, and R. D. Handy, "The antibacterial effects of silver, titanium dioxide and silica dioxide nanoparticles compared to the dental disinfectant chlorhexidine on Streptococcus mutans using a suite of bioassays," Nanotoxicology, vol. 8, no. 1, pp. 1-16, 2014.

[43] Peng, J. J.-Y., M. G. Botelho, and J. P. Matinlinna, "Silver compounds used in dentistry for caries management: a review," Journal of Dentistry, vol. 40, no. 7, pp. 531-541, 2012.

[44] Kumar, A., V. Kumar, J. Singh, A. Hooda, and S. Dutta, "Druginduced discoloration of teeth: An updated review," Clinical Pediatrics, vol. 51, no. 2, pp. $181-185,2012$.

[45] Xinyi Kuang, Vivian Chen, and Xin Xu Novel Approaches to the Control of Oral Microbial Biofilms BioMed Research International, V. 2018, Article ID 6498932, 13 pages

[46] Tascini, C.; Sozio, E.; Corte, L.; Sbrana, F.; Scarparo, C.; Ripoli, A.; Bertolino, G.; Merelli, M.; Tagliaferri, E.; Corcione, A.; et al. The role of biofilm forming on mortality in patients with candidemia: A study derived from real world data. Infect. Dis. 2018, 50, 214-219.

[47] Stratford, M. Food and beverage spoilage yeasts. In Yeasts in Food and Beverages; Querol, A., Fleet, G.H., Eds.; Springer-Verlag: Berlin/Heidelberg, Germany, 2006; pp. 335-379.

[48] Chandra, J.; Kuhn, D.M.; Mukherjee, P.K.; Hoyer, L.L.; McCormik, T.; Ghanoum, M.A. Biofilm formation by the fungal pathogen Candida albicans: Development, architecture and drug resistance. J. Bacteriol. 2001, 183, 5385-5394.

[49] Simoes, M.; Simoes, L.C.; Vieira, M.J. A review of current and emergent biofilm control strategies. LWT Food Sci. Technol. 2010, 43, 573-583.

[50] Baillie, G.S.; Douglas, L.J. Matrix polymers of Candida biofilms and their possible role in biofilm resistance to antifungal agents. J. Antimicrobial. Chemother. 2000, 46, 397-403.

[51] Ramage, G.; Bachman, S.; Patterson, T.F.; Wickes, B.L.; Lopez-Ribot, J.L. Investigation of multidrug efflux pumps in relations to fluconazole resistance in Candida albicans biofilms. J. Antimicrobial. Chemother. 2002, 49, 973-980.

[52] Mukherjee, P.K.; Chandra, J.; Kuhn, D.M.; Ghannoum, M.A. Mechanism of fluconazole resistance in Candida albicans biofilm: Phase-specific role of efflux pumps and membrane sterols. Infect. Immun. 2003, 71, 4333-4340.

[53] Al-Fattani, M.A.; Douglas, L.J. Penetration of Candida biofilms by antifungal agents. Antimicrob. Agents Chemother. 2004, 48, 3291-3297.

[54] LaFleur, M.; Kumamoto, C.A.; Lewis, K. Candida albicans biofilms produce antifungal-tolerant persister cells. Antimicrobial. Agents Chemother. 2006, 50, 3839-3846.

[55] Rajkowska, K.; Kunicka-Styczy'nska, A.; Maroszy'nska, M. Selected essential oils as antifungal agents against antibiotic-resistant Candida spp.: In vitro study on clinical and food-borne isolates. Microb. Drug Resist. 2017, 23, 18-24.

[56] Katarzyna Rajkowska, Paulina Nowicka-Krawczyk and Alina Kunicka-Styczy'nska Effect of Clove and Thyme Essential Oils on Candida Biofilm Formation and the Oil Distribution in Yeast Cells Molecules 2019, 24, 1954; doi:10.3390/molecules24101954.

[57] Fux, C.A.; Shirtliff, M.; Stoodley, P.; Costerton, J.W. Can laboratory reference strains mirror "real-world" pathogenesis? Trends Microbiol. 2005, 13, 58-63.

[58] Azeredo, J.; Azevedo, N.F.; Briandet, R.; Cerca, N.; Coenye, T.; Costa, A.R.; Desvaux, M.; Di Bonaventura, G.; Hebraud, M.; Jaglic, Z.; et al. Critical review on biofilm methods. Crit. Rev. Microbiol. 2017, 43, 313-351.

[59] Lohse, M.B.; Gulati, M.; Valle Arevalo, A.; Fishburn, A.; Johnson, A.D.; Nobile, C.J. Assessment and Optimizations of Candida albicans In Vitro Biofilm Assays. Antimicrob. Agents Chemother. 2017, 61.

[60] Montelongo-Jauregui, D.; Srinivasan, A.; Ramasubramanian, A.K.; Lopez-Ribot, J.L. An In Vitro Model forOral Mixed Biofilms of Candida albicans and Streptococcus gordonii in Synthetic Saliva. Front. Microbiol. 2016, 7, 686.

[61] 5. Uppuluri, P.; Dinakaran, H.; Thomas, D.P.; Chaturvedi, A.K.; Lopez-Ribot, J.L. Characteristics of Candida albicans biofilms grown in a synthetic urine medium. J. Clin. Microbiol. 2009, 47, 4078-4083.

[62] Kean, R.; Rajendran, R.; Haggarty, J.; Townsend, E.M.; Short, B.; Burgess, K.E.; Lang, S.; Millington, O.; Mackay, W.G.; Williams, C.; et al. Candida albicans Mycofilms Support Staphylococcus aureus Colonization and Enhances Miconazole Resistance in Dual-Species Interactions. Front. Microbiol. 2017, 8, 258.

[63] Hawser, S. Comparisons of the susceptibilities of planktonic and adherent Candida albicans to antifungal agents: A modified XTT tetrazolium assay using synchronised C. albicans cells. J. Med. Vet. Mycol. 1996, 34, 149-152. 
Citation: Mohammed Ahmed Alem, 2019. Candida biofilms properties and where we are now? Journal of Applied Sciences Research., 15(5): 34-39. DOI: 10.22587/jasr.2019.15.5.7

[64] Hawser, S.P.; Norris, H.; Jessup, C.J.; Ghannoum, M.A. Comparison of a 2,3-bis(2-methoxy- 4-nitro-5-sulfophenyl)-5-[(phenylamino)carbonyl]-2Htetrazolium hydroxide (XTT) colorimetric method with the standardized National Committee for Clinical Laboratory Standards method of testing clinical yeast isolates for susceptibility to antifungal agents. J. Clin. Microbiol. 1998, 36, 1450-1452.

[65] Ramage, G.; Vande Walle, K.; Wickes, B.L.; Lopez-Ribot, J.L. Biofilm formation by Candida dubliniensis. J. Clin. Microbiol. $2001,39,3234-3240$.

[66] Kuhn, D.M.; Balkis, M.; Chandra, J.; Mukherjee, P.K.; Ghannoum, M.A. Uses and limitations of the XTT assay in studies of Candida growth and metabolism. J. Clin. Microbiol. 2003, 41, 506-508.

[67] Taff, H.T.; Nett, J.E.; Andes, D.R. Comparative analysis of Candida biofilm quantitation assays. Med. Mycol. 2012, 50, 214-218.

[68] Nett, J.; Lincoln, L.; Marchillo, K.; Massey, R.; Holoyda, K.; Hoff, B.; VanHandel, M.; Andes, D. Putative role of $\beta-1,3$ glucans in Candida albicans biofilm resistance. Antimicrob. Agents Chemother. 2007, 51, 510-520.

[69] Pongracz, J.; Benedek, K.; Juhasz, E.; Ivan, M.; Kristof, K. In vitro biofilm production of Candida bloodstream isolates: Any association with clinical characteristics? J. Med. Microbiol. 2016, 65, 272-277.

[70] Rajendran, R.; Sherry, L.; Nile, C.J.; Sherriff, A.; Johnson, E.M.; Hanson, M.F.; Williams, C.; Munro, C.A.; Jones, B.J.; Ramage, G. Biofilm formation is a risk factor for mortality in patients with Candida albicans bloodstream infection-Scotland, 2012-2013. Clin. Microbiol. Infect. 2016, $22,87-93$.

[71] 15. Soldini, S.; Posteraro, B.; Vella, A.; De Carolis, E.; Borghi, E.; Falleni, M.; Losito, A.R.; Maiuro, G.; Trecarichi, E.M.; Sanguinetti, M.; et al. Microbiological and clinical characteristics of biofilm-forming Candida parapsilosis isolates associated with fungaemia and their impact on mortality. Clin. Microbiol. 2017.

[72] Tumbarello, M.; Fiori, B.; Trecarichi, E.M.; Posteraro, P.; Losito, A.R.; De Luca, A.; Sanguinetti, M.; Fadda, G.; Cauda, R.; Posteraro, B. Risk factors and outcomes of candidemia caused by biofilm-forming isolates in a tertiary care hospital. PLOS ONE 2012, 7, e33705.

[73] Tumbarello, M.; Posteraro, B.; Trecarichi, E.M.; Fiori, B.; Rossi, M.; Porta, R.; de Gaetano Donati, K.; La Sorda, M.; Spanu, T.; Fadda, G.; et al. Biofilm production by Candida species and inadequate antifungal therapy as predictors of mortality for patients with candidemia. J. Clin. Microbiol. 2007, 45, 18431850

[74] Kumar, C.P.; Menon, T. Biofilm production by clinical isolates of Candida species. Med. Mycol. 2006, 44, 99-101.

[75] Sherry, L.; Rajendran, R.; Lappin, D.F.; Borghi, E.; Perdoni, F.; Falleni, M.; Tosi, D.; Smith, K.; Williams, C.; Jones, B.; et al. Biofilms formed by Candida albicans bloodstream isolates display phenotypic and transcriptional heterogeneity that are associated with resistance and pathogenicity. BMC Microbiol. 2014, 14, 182.

[76] Ryan Kean, Christopher Delaney, Ranjith Rajendran, Leighann Sherry, Rebecca Metcalfe, Rachael Thomas, William McLean, Craig Williams and Gordon Ramage Gaining Insights from Candida Biofilm Heterogeneity: One Size Does Not Fit All J. Fungi 2018, 4, 12; doi:10.3390/jof4010012

[77] Brown GD, Denning DW, Gow NA, Levitz SM, Netea MG, White TC. Hidden killers: human fungal infections. Sci Transl Med. 2012 ; 4:165rv13.

[78] Pfaller MA. Epidemiology of nosocomial candidiasis: the importance of molecular typing. Braz J Infect Dis. 2000; 4:161-7.

[79] Pappas PG, Lionakis MS, Arendrup MC, Ostrosky-Zeichner L, Kullberg BJ. Invasive candidiasis. Nat Rev Dis Primers. 2018; 4:18026.

[80] Cortegiani A, Misseri G, Chowdhary A. What's new on emerging resistant Candida species. Intensive Care Med. 2019; 45:512-5

[81] Ferreira A, Prado C, Carvalho R, Dias K, Dias A. Candida albicans and non-C. albicans Candida species: comparison of biofilm production and metabolic activity in biofilms, and putative virulence properties of isolates from hospital environments and infections. Mycopathologia. 2013;175: 265-72.

[82] Chowdhary A, Sharma C, Meis JF. Candida auris: a rapidly emerging cause of hospital-acquired multidrug-resistant fungal infections globally. PLoS Pathog. 2017;13: e100 6290.

[83] Lockhart SR, Etienne KA, Vallabhaneni S, Farooqi J, Chowdhary A, Govender NP, et al. Simultaneous emergence of multidrug-resistant Candida auris on 3 continents confirmed by whole-genome sequencing and epidemiological analyses. Clin Infect Dis. 2016; 64:134-40.

[84] Bidaud A, Chowdhary A, Dannaoui E. Candida auris: an emerging drug resistant yeast—a mini-review. J Myc Med. 2018; 28:568-73.

[85] Chowdhary A, Kumar VA, Sharma C, Prakash A, Agarwal K, Babu R, et al. Multidrug-resistant endemic clonal strain of Candida auris in India. Eur J Clin Microbiol Infect Dis. 2014; 33:919-26.

[86] Forsberg K, Woodworth K, Walters M, Berkow EL, Jackson B, Chiller T, et al. Candida auris: the recent emergence of a multidrug-resistant fungal pathogen. Med Myc. 2019;57: 1-12.

[87] de Ca'ssia Orlandi Sardi J, Silva DR, Soares Mendes-Giannini MJ, Rosalen PL. Candida auris: Epidemiology, risk factors, virulence, resistance, and therapeutic options. Microb Pathog. 2018; 125:116-21.

[88] Schelenz S, Hagen F, Rhodes JL, Abdolrasouli A, Chowdhary A, Hall A, et al. First hospital outbreak of the globally emerging Candida auris in a European hospital. Antimicrob Resist Infect Control. 2016; 5:35.

[89] Cortegiani A, Misseri G, Fasciana T, Giammanco A, Giarratano A, Chowdhary A. Epidemiology, clinical characteristics, resistance, and treatment of infections by Candida auris. J Intensive Care. 2018; 6:69.

[90] Osei Sekyere J. Candida auris: a systematic review and meta-analysis of current updates on an emerging multidrugresistant pathogen. MicrobiologyOpen. 2018;7:e00578.

[91] Rossato L, Lopes Colombo A. Candida auris: what have we learned about its mechanisms of pathogenicity? Front Microbiol. 2018 ; 9:3081.

[92] Satoh K, Makimura K, Hasumi Y, Nishiyama Y, Uchida K, Yamaguchi H. Candida auris sp. nov., a novel ascomycetous yeast isolated from the external ear canal of an inpatient in a Japanese hospital. Microbiol Immunol. 2009; 53:41-4.

[93] Kathuria S, Singh PK, Sharma C, Prakash A, Masih A, Kumar A, et al. Multidrug-resistant Candida auris misidentified as Candida haemulonii: characterization

Matrix-Assisted Laser Desorption Ionization-Time of Flight Mass Spectrometry and DNA sequencing and its antifungal susceptibility profile variability by Vitek 2, CLSI broth microdilution, and Etest method. J Clin Microbiol. 2015; 53:1823-30.

[94] Mizusawa M, Miller H, Green R, Lee R, Durante M, Perkins R, et al. Can multidrug-resistant Candida auris be reliably identified in clinical microbiology laboratories? J Clin Microbiol. 2017; 55:638-40.

[95] Bao JR, Master RN, Azad KN, Schwab DA, Clark RB, Jones RS, et al. Rapid, accurate identification of Candida auris by using a novel Matrix-Assisted Laser Desorption Ionization-Time of Flight Mass Spectrometry (MALDITOF MS) database (library). J Clin Microbiol. 2018;56(4). pii: e01700-17.

[96] Lee WG, Shin JH, Young U, Kang MG, Kim SH, Park KH, et al. The first three reported cases of nosocomial fungemia caused by Candida auris. J ClinMicrobiol. 2011; 49:3139-42.

[97] Chatterjee S, Alampalli SV, Nageshan RK, Chettiar ST, Joshi S, Tatu US. Draft genome of a commonly misdiagnosed multidrug resistant pathogen Candida auris. BMC Genom. 2015; 16:686.

[98] Sharma C, Kumar N, Meis JF, Pandey R, Chowdhary A. Draft genome sequence of a fluconazole-resistant Candida auris strain from a candidemia patient in India. Genome Announc. 2015;3: pii: e00722-15.

[99] Sharma C, Kumar N, Pandey R, Meis J, Chowdhary A. Whole genome sequencing of emerging multidrug resistant Candida auris isolates in India demonstrates low genetic variation. New Microbes New Infect. 2016; 13:77-82.

[100] Auke W. de Jong, Ferry Hagen Attack, Defend and Persist: How the Fungal Pathogen Candida auris was Able to Emerge Globally in Healthcare Environments, Mycopathologia (2019) 184:353-365 